\title{
A questão penitenciária
}

\section{Luiz Antônio Bogo Chies}

Em meados dos anos de 1970 foi publicada A questão penitenciária, de Augusto Thompson, que consideramos marco de uma década que "presenciou uma espécie de tomada de consciência coletiva do problema representado pela criminalidade no Brasil urbano" (Silva, 2005, p. 15)ํ․ Entre os inúmeros méritos desse livro, destacamos o fato de ele pontuar a complexidade constitutiva da então chamada questão penitenciária, complexidade esta que se faz na tessitura de dimensões sociais, políticas e econômicas das sociedades modernas. Em 1991, já na terceira edição dessa obra, Thompson foi contundente ao delinear um horizonte para os desafios lançados por ela:

No momento, esposo o ponto de vista de que a questão penitenciária não tem solução "em si”, porque não se trata de um problema "em si”, mas parte integrante de outro maior: a questão criminal, com referência ao qual não desfruta de qualquer autonomia. A seu turno, a questão criminal também nada mais é que mero elemento de outro problema mais amplo: o das estruturas sócio-político-econômicas. Sem mexer nestas, coisa alguma vai alterar-se em sede criminal e, menos ainda, na área penitenciária (1991, p. 110).

No Brasil, a partir da publicação dessa obra em 1976, emergiram uma redimensionada perspectiva criminológica (mais crítica) e aquilo que nos permitimos chamar de sociologia nas prisões. Instigados tanto por esse
1. No campo cognitivo das questôes penitenciárias, outros importantes estudos foram desenvolvidos na mesma década, ainda que publicados posteriormente; destacamos Lemgruber ([1983] 1999), Ramalho ([1979] 2002) e Coelho ([1987] 2005). [N. E.: A data entre colchetes refere-se à edição original da obra. Ela é indicada na primeira vez que a obra é citada. Nas demais, indica-se somente a edição utilizada pelo autor]. 
2. O artigo 10 da LEP dispõe que a "assistência ao preso e ao internado é dever do Estado, objetivando prevenir o crime e orientar o retorno à convivência em sociedade" e, no artigo 11 , explicita que esta será material, jurídica, educacional, social, religiosa e sanitária. ponto de vista defendido por Thompson quanto pelos redimensionamentos contemporâneos conferidos à questão penitenciária, pretendemos acessar reflexivamente elementos teóricos e concretos de sua complexa tessitura e, desse modo, delinear premissas e abordagens que possam tensionar e enfrentar essa questão.

Nesse sentido, é relevante considerarmos que em cada sociedade a questão penitenciária - que se constitui e se manifesta por meio de expressões teóricas e concretas (políticas, institucionais e práticas) dos paradoxos e das contradições entre os discursos e as promessas acerca do castigo penal pretensamente civilizado (a privação da liberdade) e a realidade de sua execução pelos Estados modernos - evidencia-se contemporaneamente nas intersecções das esferas da política penal, criminal e social e por meio de dinâmicas de complementaridade e/ou de substituiçôes.

$\mathrm{Na}$ expectativa de justificar o presente esforço, cabe mencionar que, se há muito a questão penitenciária já se encontra em evidência, o contexto contemporâneo dos sistemas prisionais - ao envolver, a par da elevação das taxas de encarceramento, o abandono explícito ou mascarado das finalidades ético-teleológicas da punição (via de regra, acompanhado por deteriorações das condições de execução da pena) - é o que mantém essa questão relevante e atual, tornando-a sobretudo mais visível e inevitável.

Se em realidades europeias e estadunidenses esse contexto, desde a década de 1970, se agravou com a crise e o abandono do que David Garland denominou previdenciarismo penal - "uma estrutura [...] híbrida, que combinava o legalismo liberal do devido processo legal e da punição proporcional com um compromisso correcionalista de reabilitação, bem-estar e o saber criminológico especializado" (2008, p. 93) -, no Brasil, o panorama é ainda mais paradoxal.

Como observa Alessandra Teixeira (2006), somente em 1984, com a Lei 7210 , a Lei de Execução Penal (LEP), o ideal ressocializador e humanizador da prisão consolida-se na legislação e na política criminal brasileira (quando já estava em declínio na Europa e nos Estados Unidos). Com efeito, ainda que a LEP tenha registrado avanços na positivação de direitos sociais às populaçôes encarceradas - o que se pode verificar pela correlação entre as assistências que ela destina aos presos ${ }^{2}$ e os direitos sociais previstos no artigo 6 da Constituição Federal de 1988 - essa diferença de temporalidade, isto é, a tardia adesão brasileira a um marco pretensamente civilizatório da punição, pode ser creditada como uma das causas da parca eficácia dos dispositivos legais da LEP. 
Entretanto, o cenário complexifica-se quando verificamos que, sobretudo na última década, duas realidades antagônicas - ainda que também complementares e dialógicas - se instauraram no país. De um lado, temos o incremento quantitativo do encarceramento: em 2011, o Brasil superou a marca de meio milhão de presos e só nos últimos dez anos promoveu a elevação da taxa de aprisionamento de 133 para 269,7 pessoas por 100 mil habitantes ${ }^{3}$. De outro lado, não obstante o agravamento da precariedade das condições de encarceramento real dessa superpopulação prisional, experimentamos significativa produção de normas e diretrizes políticas que, ao menos no papel e no discurso, refina e sofistica as promessas e perspectivas de direitos sociais aos presos: em 2003, o Plano Nacional de Saúde no Sistema Penitenciário; em 2009, a Lei 11942 alterou a LEP visando assegurar às mães presas e aos recém-nascidos condições mínimas de assistência; em 2010, a Lei 12313 também alterou a LEP a fim de prever a assistência jurídica ao preso e atribuir competências à Defensoria Pública e, por último, ainda em 2010, as Diretrizes Nacionais para Educação nas Prisões.

Portanto, apesar de uma consistente reflexividade crítica já consolidada acerca das práticas punitivas de encarceramento, verifica-se a insistente permanência de uma governabilidade que, além de mantê-las, renova e redimensiona os discursos e as promessas da operacionalidade dessas práticas. E mais, esta se faz acompanhada de crenças sociais que também se mantêm fiéis à exigibilidade da prisão.

Tais políticas de governabilidade e tais crenças se constituem a partir de tramas complexas, pois ambas se alimentam do fato de o castigo ser uma instituição social e de o conflito ser tanto uma dinâmica de interação quanto de omissão (ao desviar de uma possibilidade de ação). Entretanto, a diversidade das representações, dos discursos e das práticas que gravitam e se produzem no entorno desses fenômenos favorece que eles sejam apropriados e instrumentalizados por funcionalidades sociais que nem sempre se direcionam à criação de sociabilidades humano-dignificantes. Esta mesma diversidade permite, ainda, que se ofusquem os resultados das apropriações/instrumentalizações perversas, haja vista que representações, discursos e políticas que deveriam ser antagônicos acabam por se complementar, o que prejudica a percepção dos limites entre o que é civilizado e o que é violência.
3. Dados disponíveis no portal eletrônico do Ministério da Justiça. 


\section{Do castigo à penalidade e desta ao poder punitivo}

Como primeiro aporte reflexivo para melhor delinear a complexidade da questão penitenciária, enfocaremos a conexão e simultânea distinção - na condição de espécie de um gênero - entre esta e o castigo, o que é entendido como uma instituição social, conforme propõe Garland:

As instituições sociais - que incluem a família, a lei, a educação, o governo, o mercado, o exército e a religião, entre outras - são conjuntos de práticas sociais sumamente estruturadas e organizadas. São os meios estáveis com os quais, de maneira ordenada e normativa, uma sociedade maneja certas necessidades, relações, conflitos e problemas recorrentes para que as relaçôes sociais sejam razoavelmente estáveis e diferenciadas. As instituições geralmente evoluem lentamente, no transcurso de um período amplo, de maneira que seu caráter presente é moldado pela história e pela tradição, assim como pelas funções contemporâneas que desempenham (1999, p. 327).

Compreender o castigo como instituição social implica pensá-lo em

4. A “'sobredeterminação' não é outra coisa que o reconhecimento claro de que uma variedade de causas - variedade, não infinidade - forma parte de qualquer acontecimento histórico, e que cada ingrediente na experiência histórica pode ter uma variedade não infinidade - de funçôes" (Gay apud Garland, 1999, p. 325). termos de complexidade, de objetivos múltiplos e de sobredeterminações ${ }^{4}$; considerá-lo como um acontecimento histórico, isto é, como sistema funcional e forma distinta de vida, o qual, por sua vez, depende de outras formas e relações sociais, ou seja, condiciona-se por um conjunto de forças históricas e sociais; reconhecer que possui um marco institucional próprio e apoia uma série de práticas normativas e significantes que, por sua vez, produzem uma gama de efeitos (cf. Garland, 1999, p. 328-329). Significa, portanto, "aprender a ver tanto sua integridade - já que instituição-, quanto sua relatividade - já que instituição social” (Idem, p. 328).

A complexidade do castigo é que nos permite reconhecer contribuições e acertos, mas também, via de regra, incompletudes em abordagens de referenciais teóricos tão distintos como são, por exemplo, os de Émile Durkheim (1995) e Michel Foucault (1991), haja vista que:

O castigo pode ser visto como uma espécie de aparato técnico; um meio instrumental para atingir um fim [...] uma relação coercitiva entre o Estado e o transgressor [...] um procedimento legal, uma forma de poder, um instrumento de dominação de classe, a expressão de um sentimento coletivo, uma ação moral, um acontecimento ritual ou a encarnação de certa sensibilidade. E, como temos visto, cada uma dessas imagens capta certo aspecto do fenômeno, uma determinada verdade sobre seu 
caráter que queremos manter, mas o faz de maneira fragmentada, deixando-o fora de foco tanto quanto aquilo que o abarca (Garland, 1999, p. 326).

A prisão, por ser uma manifestação sócio-histórica do castigo, compartilha essa complexidade. Desenvolve-se, entretanto, associada às sociedades modernas, contexto no qual se consolida, se dinamiza, se dimensiona e se redimensiona acompanhando as próprias transformações e permanências das expressões sociais, políticas e econômicas da modernidade. A partir desse vínculo entre prisão e sociedade moderna, tentaremos compreender as sobredeterminações que favorecem a constituição da questão penitenciária.

$\mathrm{O}$ vínculo entre determinada sociedade e uma ou mais modalidades concretas de castigo também nos permite falar de um sistema de penalidade(s), organizado e gerido socialmente (de forma democrática ou não) que emerge e se mantém em uma sociedade histórica particular. Tal sistema inclui os discursos de justificação e as dimensões de gestão política das punições que o compõe. Como não poderia deixar de ser, esse sistema corresponde a construções compatíveis e necessárias à manutenção do modelo societário no qual emerge: assim, se vinculado a estruturas sociais igualitárias e comunitárias, permitir-se-á assumir sentidos e funcionalidades diversos daqueles que estruturas sociais desiguais e individualistas comporão (de forma velada ou explícita).

Não obstante, há ainda que se reconhecer que os sistemas de penalidades exigem a si próprios a conquista de níveis de legitimidade que lhes garantam uma expectativa de vigência social não identificada apenas como manifestação de violências, mas também como um instrumento de expressão e afirmação da moralidade coletiva (com todos os paradoxos que essa moralidade possa conter).

Esta é, pois, uma bidimensionalidade básica do enfoque que assumimos como orientador da compreensão da complexidade da questão penitenciária e que, em especial na contemporaneidade, será impactada - em tensa e paradoxal relação - por uma feição peculiar dos sistemas de penalidades da modernidade: o poder punitivo que, outrora existente no império romano (cf. Zaffaroni, 2011, p. 30), ressurge como consentâneo da própria sociogênese do Estado moderno, a qual implicou a concentração nas mãos do soberano de monopólios como os do exército, da tributação e da jurisdiçãao (cf. Elias, 1993).

Em termos de gestão da conflitualidade e do castigo, a "característica diferenciada do poder punitivo é o confisco do conflito, ou seja, a usurpação 
do lugar de quem sofre o dano ou é vítima por parte do senhor (poder público)" (Zaffaroni, 2011, p. 30). Trata-se, para Zaffaroni, de um poder com tendências totalitárias, que se pauta pela supremacia do interesse do dominus/soberano (pessoal ou impessoal) e, portanto, atua na preservação deste interesse mesmo que em detrimento das partes envolvidas no conflito. Foucault (1999, pp. 76-77) também se referencia a este processo, mencionando-o como o momento da invenção da infração.

Seja em sua percepção como "invenção da infração", seja como ressurgimento do "poder punitivo", esse processo é inicialmente sobredeterminado por uma funcionalidade política no curso das concentrações de um poder soberano que, mais tarde, desaguariam na formação dos modernos Estados-nação.

As fundações do controle do crime no século XX foram lançadas séculos antes [...]. No início desse processo, na condição de detentores da contestada e instável autoridade que caracterizava a Europa no limiar da Idade Moderna, lordes soberanos vitoriosos sustentavam sua promessa de pax et justitia aos seus súditos, enquanto seus soldados lutavam para pacificar o território recentemente conquistado e para impor a "paz do Rei”. A garantia de "lei e ordem" (que originalmente significava a supressão de poderes alternativos e de fontes alternativas de justiça, assim como o controle da conduta criminosa e desordeira) era, pois, desde o início, um aspecto crucial do poder soberano. [...] Tratava-se do processo através do qual se impunha a vontade soberana do Rei contra seus inimigos e contra os súditos rebeldes ou que não respeitassem suas leis. Somente tempos depois a aplicação da lei viria a denotar o sistema estatal de busca e punição dos criminosos (Garland, 2008, p. 96).

Nessa dimensão da tessitura complexa do sistema de penalidades da modernidade, a transição do poder pessoal do soberano-rei para o poder impessoal do Estado-república não significou o abandono do poder punitivo com suas características diferenciais (confisco do conflito e supremacia do interesse do dominus) - até mesmo porque era valioso instrumento de controle social também para esse modelo de dominação/governabilidade -, mas seu redimensionamento, sua colonização por justificações, agora, não só mais voltadas à defesa da sociedade do que à defesa/vingança do soberano em si (e, portanto, gradualmente menos salientes em sua característica de retribuição punitiva), como também a estratégias de reforma do sentenciado.

Foucault localiza aí o sentido utilitário, e por que não paradoxal, do tradicional discurso criminológico: "Desde que se suprima a ideia de vingança, 
que outrora era o feito do soberano, do soberano atacado em sua própria soberania pelo crime, a punição só pode ter significação em uma tecnologia de reforma" (2003, p. 169).

Trata-se de atuar por intermédio da construção de um discurso técnico e científico sobre crime, pena e criminoso na satisfação da bidimensionalidade básica de legitimação de um sistema, ou seja, de conectá-lo à aceitabilidade e à coerência de uma conduta moral coletiva, além de estruturá-lo como expressão eficaz do poder do governo/Estado para impor e manter sua característica ordem social.

Mas antes que sigamos nessa direção, é pertinente que direcionemos nossa atenção para outra perspectiva de abordagem, a qual atuou no desvelamento das conexões entre a gênese da questão penitenciária e as dimensões econômica e produtiva das transiçôes à sociedade moderna.

\section{A economia política da penalidade}

Em sua síntese, Alessandro de Giorgi assim define a economia política da penalidade:

Trata-se de uma orientação da criminologia crítica, de derivação principalmente marxista e foucaultiana, que investigou, sobretudo a partir dos anos 1970, a relação entre economia e controle social, reconstruindo as coordenadas da relação que parece manter juntas determinadas formas de produzir e determinadas modalidades de punir (2006, p. 31).

Georg Rusche e Otto Kirchheimer, em obra inaugural dessa perspectiva, partem da premissa de que "Todo sistema de produção tende a descobrir punições que correspondam às suas relações de produção" ([1939] 1999), p. 18) e promovem, assim, um redimensionamento cognitivo em relação aos sistemas de penalidades:

A transformação em sistemas penais não pode ser explicada somente pela mudança das demandas do crime [sociedade] contra o crime, embora esta luta faça parte do jogo. [...] É, pois, necessário pesquisar a origem e a força dos sistemas penais, o uso e a rejeição de certas punições, e a intensidade das práticas penais, uma vez que elas são determinadas por forças sociais, sobretudo pelas econômicas e consequentemente fiscais (Idem, ibidem). 
5. Essa conexão, sob distintas abordagens, ora mais vinculadas às políticas penais, ora mais às políticas sociais, foi retomada por Dario Melossi e Massimo Pavarini (1980), Michel Foucault (1991) e Robert Castel (1998).
Quanto às transformaçôes punitivas na transição à modernidade, eles são precisos ao considerar que:

Os métodos de punição começaram a sofrer uma mudança gradual e profunda em fins do século XVI. A possibilidade de explorar o trabalho de prisioneiros passou a receber crescentemente mais atenção. Escravidão nas galés, deportação e servidão penal através de trabalhos forçados foram introduzidos, os dois primeiros por um certo tempo; o terceiro como precursor hesitante de uma instituição que tem permanecido até o presente. [...] Estas mudanças não resultaram de considerações humanitárias, mas de um certo desenvolvimento econômico que revelava o valor potencial de uma massa de material humano completamente à disposição das autoridades (Idem, p. 39).

Em síntese, os autores demonstram o vínculo entre as mudanças nas modalidades punitivas e as necessidades políticas, econômicas e produtivas da sociedade.

No caso específico da prisão e, por consequência, da questão penitenciária, tal premissa permitiu que esses pesquisadores conectassem, de forma pioneira, práticas (tais como as Poor Laws inglesas) hoje consideradas os "mais remotos e cambiantes arranjos de política social no contexto da relação entre o Estado e o pobre" (Pereira, 2009, p. 61) com a estruturação de sistemas de penalidades - desvelando, inclusive, o papel das workhouses nessa gênese - e sentenciassem: "A história da política pública para mendigos e pobres somente pode ser compreendida se relacionamos a caridade com o direito penal" (Rusche e Kirchheimer, 1999, p. 52)5.

Assim, o desvelamento de uma conexão funcional entre, por um lado, o sistema de penalidades e, por outro, as possibilidades de controle/gestão da força e do mercado de trabalho, constituiu-se num primeiro e mais característico enfoque da economia política da penalidade.

Com Foucault (1991), as perspectivas dessa abordagem ampliam a percepção das ambivalências funcionais do sistema de penalidades, uma vez que são identificados diferenciados objetivos atribuídos e desenvolvidos pela prisão. Em síntese, nós os teremos tanto como objetivos ideológicos, que nos remetem à repressão e à redução da criminalidade, quanto como objetivos reais, isto é, a repressão seletiva da criminalidade e a organização da delinquência, definida como tática política de submissão.

As duas principais funcionalidades do sistema de penalidades, então, consubstanciar-se-iam na docilização dos corpos e na produção da delinquência, permitindo por parte das dinâmicas de poder e de dominação social 
a extração de ganhos estratégicos, seja porque a docilização dos corpos se dirige também à utilização econômica das forças corporais (a domesticação do delinquente em trabalhador), seja porque a produção da delinquência contribui para a moralização da classe trabalhadora e para o ocultamento da criminalidade que se pode associar à classe dominante.

Não obstante as contribuições da economia política da penalidade, um viés de ortodoxia explicativa e analítica no vínculo entre mercado de trabalho e prisão afetou sua manutenção como grade teórico-cognitiva na questão penitenciária - eis que (nessa ortodoxia) se demonstrou insuficiente para o enfrentamento das complexidades relacionais das estruturas sociais contemporâneas com os sistemas de penalidades.

Loïc Wacquant (2007), por inserir em sua análise as dimensões simbólicas da relação entre estrutura social e punição, e não somente as instrumentais, explicitamente se desassocia daquela perspectiva (2007, p.17), ainda que suas premissas partam da identificação do redimensionamento da conexão entre as políticas sociais e as políticas penais e seus resultados se compatibilizem com um novo momento (e percepção) das ambivalentes funcionalidades do sistema de penalidades. Estas servem então para:

[...] neutralizar e estocar fisicamente as frações excedentes da classe operária [...] impor a disciplina do trabalho assalariado dessocializado entre as fraçôes superiores do proletariado e os estratos em declínio e sem a segurança da classe média [...] [e simbolicamente] reafirmar a autoridade do Estado e a vontade reencontrada das elites políticas de enfatizar e impor a fronteira sagrada entre cidadãos de bem e as categorias desviantes, os pobres "merecedores" e os "não merecedores", aqueles que merecem ser salvos e "inseridos" (mediante uma mistura de sançōes e incentivos) no circuito do trabalho assalariado instável e aqueles que, doravante, devem ser postos no índex e banidos, de forma duradoura (Wacquant, 2007, pp. 16-17).

Diante disto e ao valorar os limites e as possibilidades conferidas pelas perspectivas da economia política da penalidade, reconhecemos a manutenção destas como referencial teórico relevante na cognição, tensionamento e enfrentamento da questão penitenciária. Contudo, acompanhando Giorgi (2006), tomamos essa perspectiva atualizada da economia política da penalidade em seu viés contributivo - não, portanto, o ortodoxo -, haja vista que tal permitirá também avançar sobre as dimensóes simbólicas dos sistemas de penalidade, como também requer e sustenta a já mencionada abordagem de Wacquant (2007). 
Nesse sentido, torna-se indispensável considerar tanto a dimensão instrumental quanto a dimensão simbólica da instituição carcerária. A dimensão instrumental nos permite iluminar as origens da penitenciária e as funçôes econômicas imediatas que ela assumia, sendo a principal delas a produção de uma forma de trabalho disciplinada e disponível à valorização capitalista. A dimensão simbólica, por sua vez, permite-nos explicar o motivo do "sucesso histórico" aparente da instituição carcerária (Giorgi, 2006, p. 45).

Mantém-se, pois, o principal fio condutor da abordagem quanto à penalidade, a saber, o de que ela

[...] absorve uma função diversa e posterior em relação à função manifesta de controle dos desvios e defesa social da criminalidade. Esta função "latente" pode ser descrita situando-se os dispositivos de controle social no contexto das transformações econômicas que perpassam a sociedade capitalista e as contradiçôes que dela derivam (Idem, p. 36).

Dos sentidos aos discursos e à invenção da pena neutra

Ao retomarmos a perspectiva de exigência da bidimensionalidade dos sistemas de penalidades para fins de vigência social dos mesmos, a reflexão que propomos avança na percepção dos sentidos que se constroem no entorno desses sistemas e que se vinculam às capacidades (ou pretensóes) que estes têm de expressar e operacionalizar níveis e intensidades de coesão moral e civilizatória da sociedade (cf. Elias, 2006, pp. 25, 30).

Nessa dimensão, situa-se o clássico enfoque de Durkheim, que propõe ser a verdadeira função da pena "manter intacta a coesão social, mantendo toda a vitalidade da consciência comum" (1995, p. 81). Todavia, esta também é uma dimensão que em si mesma é complexa, pois se defronta com o desafio de tornar admissível - sobretudo diante de avanços civilizatórios - a crueldade de diversas modalidades de castigo. Cabe mencionar a recomendação de Pedro Bodê, quando nos instiga a pensar a punição a partir de uma antropologia da crueldade e da dor, haja vista que "[...] toda punição implicaria imposição de uma certa quantidade de dor [...] [e que as] práticas de imposição de dor não são, é verdade, necessariamente percebidas como cruéis por aqueles que dela se utilizam, ou são vistas como crueldades necessárias e/ou legítimas” (2005, pp. 103-104).

Frédéric Gros, ao se debruçar sobre "a história das razões que o homem constrói para praticar ou aplicar o mal a outro homem” (2001, p. 11), 
identifica a articulação de quatro sistemas de justificação, os quais se desenvolvem em quatro discursos:

- um discurso sagrado ou moral, suspenso de um interdito ou de uma norma universal transgredida. Punir é recordar a lei [...] em que o castigável aparece como traidor, maldito, ou legislador de seu próprio sofrimento;

- um discurso político-econômico que pretende regular-se pelos interesses imanentes de uma comunidade ameaçada. Puniré defender a sociedade; [...] em que o castigável assume as figuras mutáveis do monstro doente, do inimigo, do pequeno déspota, do enganador e do mau calculador;

- um discurso psicopedagógico que pretende obter pela pena a transformação do condenado. Punir é educar um indivíduo; [...] em que o castigável será considerado um indivíduo educável;

- um discurso ético-jurídico que tenta ultrapassar o lado ético da vingança para pensar uma justiça relacional. Punir é transformar o sofrimento em infelicidade [...] (2001, pp. 12-13).

Mas, conforme Gros (2001, p. 13), não se trata da escolha de um discurso contra os outros. Se no campo da filosofia moral e da punição é preciso aprofundá-los em seus limites e pertinências, compreendendo a necessidade de se transitar entre eles, propomos que o lugar desses discursos seja justamente a tensão gerada no seu embate - agora num sentido foucaultiano; discursos que se constroem e sustentam um sistema de penalidades sobretudo a partir das fontes estatais e oficiais de governabilidade e que, em nosso objeto mais específico, se entrelaçam na constituição da trama complexa da questão penitenciária.

Assim, se é importante reconhecermos que há um sentido civilizatório a permear a história das penalidades, é imprescindível também atentarmos para as apropriações ambíguas do poder punitivo em relação a esse sentido. Elas resultam na construção de discursos que, de forma ambivalente, podem mascarar paradoxos e sobretudo ausências de compromissos políticos humano-dignificantes.

Cabe destacar, ainda que de modo sintético, a percepção de que todas as instrumentalizaçóes que as perspectivas da economia política da penalidade puderam desvelar na relação entre Estado e punição fizeram-se sempre no acompanhamento de atribuiçôes de sentidos racionais, humanizantes e civilizatórios das penalidades, os quais foram incorporados nos discursos oficiais e até operacionalizados por meio de políticas públicas. 
No transcorrer dos séculos XVII e XVIII, a prisão emerge como pena basilar das sociedades ocidentais com o respaldo das formulações iluministas e contratualistas que transformaram a obra de Cesare Beccaria - Dos delitos e das penas (originalmente publicada em 1764) - num ícone da humanização dos castigos. A punição privativa de liberdade se afirmará e se consolidará no século XIX, tendo suas justificações sido densificadas pelas abordagens cognitivas da escola liberal clássica de direito penal e da criminologia positivista, as quais viabilizaram, conforme afirma Alessandro Baratta (1998), a constituição de uma ideologia da defesa social assentada em seis princípios:

a) Princípio de legitimidade. O Estado, como expressão da sociedade, está legitimado para reprimir a criminalidade. [...]

b) Princípio do bem e do mal. O delito é um dano para a sociedade. O delinquente é um elemento negativo e desfuncional do sistema social. [...]

c) Princípio de culpabilidade. O delito é expressão de uma atitude interior reprovável. [...]

d) Princípio do fim ou da prevenção. A pena não tem - ou não tem unicamente - a função de retribuir, mas também a de prevenir o crime. [...]

e) Princípio da igualdade. A criminalidade é a violação da lei penal, e como tal é o comportamento de uma minoria desviada. A lei penal é igual para todos. A reação penal se aplica de modo igual aos autores de delitos.

f) Princípio do interesse social e do delito natural. [...] Os interesses protegidos pelo direito penal são interesses comuns a todos os cidadãos [...] (Baratta, 1998, pp. 36-37).

Já no século XIX, o então chamado discurso disciplinador, vinculado sobremodo às primeiras experiências e justificações do encarceramento a partir das workhouses, será gradualmente suplantado por um discurso correcionalista, que se embasa na ideia de se corrigir o encarcerado, tomado como elemento disfuncional no sistema social. Esse discurso causou impactos no Brasil desde sua emancipação política, em 1822, haja vista as disposições acerca dos crimes e das penas que se inscrevem na Constituição de 1824 e os termos do Código Criminal do Império de 1830 e do Código de Processo Criminal de 1832, que levaram à construção das casas de correção de São Paulo e da Corte ainda na primeira metade daquele século (cf. Salla, 1999).

Do discurso correcionalista como justificação da penalidade de sequestro se avançará, em especial no século XX, ao previdenciarismo penal. Garland baliza esse processo em dois axiomas: 
O primeiro destes axiomas - nascido do "milagre do crime" do final do século XIX e criado pelo otimismo liberal do século XX - postulava que a reforma social juntamente com a prosperidade econômica acabariam por reduzir a frequência do crime. [...] O segundo axioma, igualmente produto daquele período histórico específico, preconizava que o Estado é responsável por cuidar dos criminosos, bem como por sua punição e seu controle (2008, p. 110).

Ainda conforme Garland, o previdenciarismo penal:

[...] vigorosamente desenvolvido nos anos 1950 e 1960, [...] era, nos anos 1970, a política estabelecida tanto na Grã-Bretanha quanto nos Estados Unidos. Seu axioma básico - medidas penais devem, sempre que possível, se materializar mais em intervenções reabilitadoras do que na punição retributiva - proporcionou o aperfeiçoamento de uma rede de princípios e práticas inter-relacionados (2008, p. 104).

E, em todos os sentidos, o previdenciarismo penal redimensionou e revitalizou a conexão entre políticas penais e políticas sociais, o que impactou também os discursos e as práticas penitenciárias brasileiras, haja vista a já mencionada perspectiva assumida pela LEP em 1984.

De todo esse percurso, destaca-se que o Ocidente produziu e inventou no decorrer de suas experiências prisionais aquilo que Thierry Pech caracteriza como um novo sonho penitenciário: "erradicar os sofrimentos prisionais, controlar a prisão, sujeitar as suas decisões a processos imparciais e contraditórios, solicitar as capacidades de iniciativa do detento, firmar os seus projetos [...]" (2001, pp.139-140), para afirmar em seguida a emergência da utopia da pena neutra: "Uma pena liberta de toda referência ao sagrado, de toda violência, de toda paixão vindicativa, de toda intenção moral e de todo o arbitrário na sua execução" (Idem, p. 139).

A crise, ou mesmo a impossibilidade, desse sonho penitenciário e da correlata manutenção de seus conteúdos (ou ao menos de fragmentos destes) nos discursos e políticas produz a emergência e o redimensionamento contemporâneo da questão penitenciária.

Com efeito, nessa percepção dos sentidos e dos discursos em relação ao castigo e aos sistemas de penalidade e, até mesmo, nesse vislumbre de uma nova utopia, revela-se o adensamento da complexidade da questão penitenciária. Por esse motivo, o que foi desenvolvido nesta seção não se destina a suscitar uma escolha entre este ou aquele sentido ou discurso; ao contrário, é 
preciso perceber as várias dimensões a serem tensionadas no enfrentamento da sua tessitura complexa.

Um complexo ambiente num complexo sistema

Contudo, a complexidade não se esgota nos aspectos já mencionados; ela avança de uma dimensão à outra, de um nível ao outro dos elementos e das tramas componentes da questão penitenciária.

Como adequadamente sugere Carlos Aguirre, as prisões (instituição e ambiente carcerário) já são em si muitas coisas ao mesmo tempo:

[...] instituições que representam o poder e a autoridade do Estado; arenas de conflito, negociação e resistência; espaços para a criação de formas subalternas de socialização e cultura; poderosos símbolos de modernidade (ou de ausência dela); artefatos culturais que representam as contradições e tensões que afetam as sociedades, empresas econômicas que buscam manufaturar tanto bens de consumo como eficientes trabalhadores; centros para a produção de distintos conhecimentos sobre as classes populares; e, finalmente, espaços onde amplos segmentos da população vivem parte de suas vidas, formam suas visões de mundo, entrando em negociações e interação com outros indivíduos e com autoridades do Estado (2009, p. 35).

E, mais do que isso, estão inseridas naquilo que costumamos chamar de sistema penal:

Chamamos de "sistema penal" ao controle social punitivo institucionalizado, que na prática abarca desde que se detecta ou supōe detectar-se uma suspeita de delito até que se impõe e executa uma pena, pressupondo uma atividade normativa que cria a lei que institucionaliza o procedimento, a atuação dos funcionários e define os casos e condições para esta atuação. Esta é a ideia geral de "sistema penal" em sentido limitado, englobando a atividade do legislador, do público, da polícia, dos juízes e funcionários e da execução penal (Zaffaroni e Pierangeli, 1997, p. 70)

Nesse contexto, Hulsman e Celis fazem uma contundente crítica ao funcionamento do sistema penal e das instituiçôes prisionais:

Quando o discurso oficial (político, jurídico, científico, etc.) faz referência ao sistema penal, implicitamente o considera um sistema racional, concebido, criado e controlado pelo homem. [...] Você retoma essa mesma imagem quando pensa: 
"Existem a polícia, os juízes, a administração penitenciária [...]. Existem o Parlamento que faz as leis e os tribunais que as aplicam. Cada elemento intervém ao seu tempo e funciona em harmonia com os outros. É um sistema sério, graças ao qual a justiça é prestada e a sociedade libertada de elementos antissociais que perturbam sua evolução normal [...]”. Eis uma visão totalmente abstrata (1993, pp. 58-59).

\section{Entretanto:}

Cada corpo desenvolve, assim, critérios de ação, ideologias e culturas próprias e não raro entram em choque, em luta aberta uns contra os outros. No entanto, são vistos como um conjunto, "prestando justiça", "combatendo criminalidade". Na realidade, o sistema penal estatal dificilmente poderia alcançar tais objetivos. Como todas as grandes burocracias, sua tendência principal não se dirige para objetivos externos, mas sim para objetivos internos, tais como atenuar dificuldades, crescer, encontrar um equilíbrio, velar pelo bem-estar de seus membros - numa palavra, assegurar sua própria sobrevivência. $O$ processo de burocratização e profissionalização, que transpassa o sistema penal, faz dele um mecanismo sem alma (Idem, pp. 59-60).

Não obstante a pertinência da crítica sob um viés de análise e de interpretação, o que propomos é inserir outro paradigma cognitivo para que se reconheça, por sua vez, outra dimensão de complexidade da questão penitenciária.

Com base nas abordagens de Edgar Morin (2007), sugerimos que nossa atenção se dirija menos para a denúncia de uma disfuncionalidade sistêmica e mais para a compreensão de uma complexidade sistêmica que:

[...] manifesta-se, sobretudo, no fato de que o todo possui qualidades e propriedades que não se encontram no nível das partes consideradas isoladamente e, inversamente, no fato de que as partes possuem qualidades e propriedades que desaparecem sob o efeito das coaçôes organizacionais do sistema. A complexidade sistêmica aumenta, por um lado, com o aumento do número e da diversidade dos elementos, e, por outro, com o caráter cada vez mais flexível, cada vez mais complicado, cada vez menos determinista (pelo menos para um observador) das inter-relações (interações, retroações, interferências etc.) (2007, p. 291).

Como cerne dessa observação - a qual implica no reconhecimento de que, em termos de complexidade sistêmica, o todo é mais e menos do que a soma das partes (assim como mais do que o próprio todo) e de que as partes 
eventualmente são mais do que o todo, sendo este insuficiente, incerto e conflituoso (cf. Idem, pp. 261-264) -, destaca-se a perspectiva de identificação de emergências e de inibições como situações, dinâmicas, efeitos que só se produzem num sentido positivo ou negativo a partir da organização sistêmica. Então, aquilo que muitas vezes creditamos como disfuncional não seria mais do que circunstâncias emergentes ou efeitos de inibiçôes da própria funcionalidade sistêmica.

Sem que possamos avançar o detalhamento do paradigma da complexidade, a partir de Morin, bem como da aplicabilidade contributiva desse paradigma para com a questão penitenciária (o que já consideramos suficientemente sinalizado), indicamos que o conjunto de possíveis elementos que compõe as tramas dos objetos - as quais, nesse campo, se conformaram como pautas de cognição, tensionamento e enfrentamento - sempre se perfazem por meio de elevado número de elementos isoláveis, estes que, muitas vezes, em si já se compõem como outros sistemas complexos.

O sistema penal, como mencionado, compõe-se ao menos de quatro sistemas isoláveis: o legislativo, o policial, o judiciário e o de execução penal (no caso brasileiro, administrativo penitenciário), todos permeados pela sociedade mais ampla em que estão inseridos. Numa perspectiva aparentemente mais restrita, mas não menos complexa, um ambiente prisional (e suas consequentes dinâmicas) envolve um grande número de grupos que sequer são internamente homogêneos - encarcerados, agentes de segurança, técnicos, funcionários da administração. Esse ambiente ainda recebe o impacto de grupos externos, tais como familiares, instituiçôes religiosas, educacionais, do terceiro setor e, inclusive, instituiçôes criminais.

Há, portanto, uma sobrecarga de aspectos que não pode ser ignorada quando se enfoca qualquer objeto ou dimensão da questão penitenciária. Essa sobrecarga, que deve ser reconhecida desde o plano de configuração das realidades, ainda recepciona o impacto de elementos políticos e sociais mais amplos e dela indissociáveis, bem como se constitui por meio deste.

\section{Delineamento de premissas e indicações de abordagem}

Como estipulamos no início deste artigo, nossa expectativa é a de contribuir para o delineamento da questão penitenciária em sua complexidade, alertando para as armadilhas envolvidas neste âmbito.

Podemos agora, ainda que dentro dos limites espaciais deste artigo e apesar de eventuais carências teóricas, propor as seguintes premissas: 
1. Da complexidade - que se expressa tanto no nível fenomênico mais amplo do castigo como instituição social e que repercute também nos sistemas de penalidades concretos, quanto no nível sistêmico-organizacional e operacional destes; essa premissa nos conduz a um olhar atento às possíveis multidimensionalidades e multifuncionalidades dos objetos concretos a serem conhecidos, tensionados e enfrentados, bem como às interações, retroações e interferências dinâmicas destes com eventuais situações de emergências e inibições.

2. Das sobredeterminações sócio-históricas - que nos conduz à atenção e ao desvelamento das peculiaridades conjunturais e contextuais da questão penitenciária em suas dimensões e redimensionamentos espaço(geográfico)-temporais, evitando a armadilha cognitiva de generalizações inadequadas e importações equivocadas.

3. Da construção discursiva - que impõe o reconhecimento das dimensões de sentido simbólico e ideológico da penalidade prisional como complementar das apropriações instrumentais que dela se fazem.

Tais premissas, que não consideramos exaustivas, dialogam entre si, motivo pelo qual, por exemplo, a complexidade e as sobredeterminaçôes sócio-históricas devem ser adotadas como favorecedoras de construções discursivas ambivalentes.

Na Figura 1, apresentamos uma síntese do percurso que aqui desenvolvemos.

Imagem sintese de delineamento da questão penitenciária

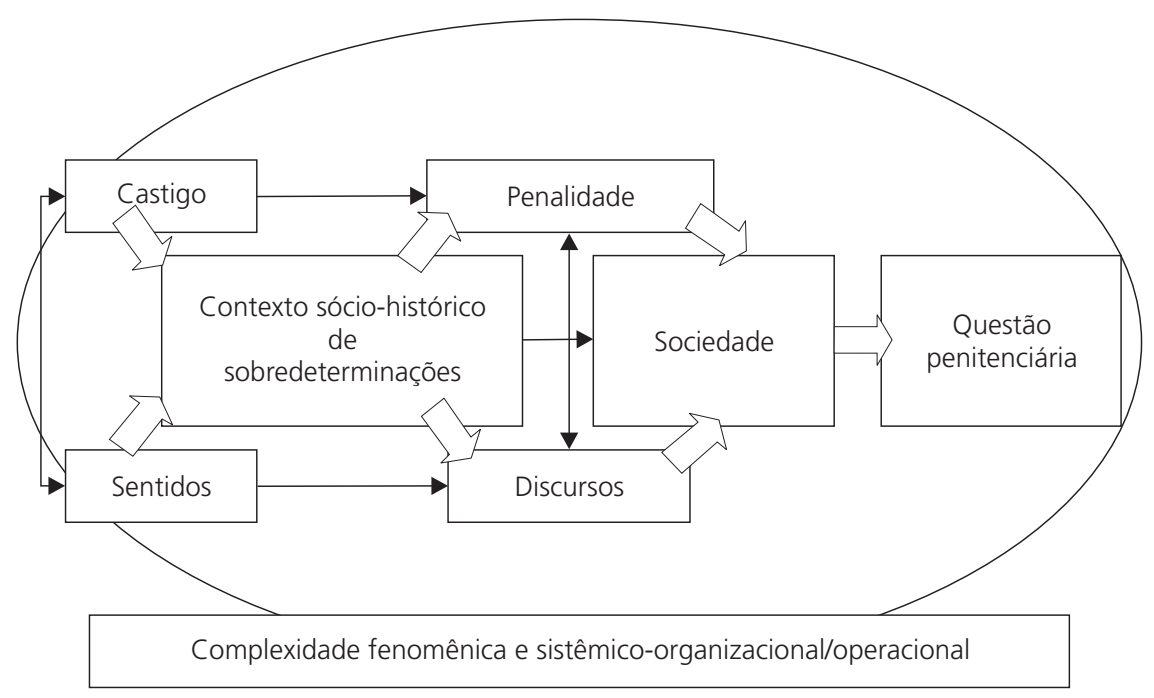


Com base nelas, entendemos ser possível lançar uma segunda noção acerca da questão penitenciária. Noção que se constitui no reflexo (isto é, como e por meio de manifestaçôes concretas e simbólicas) de sobredeterminaçōes sócio-históricas da operacionalidade do castigo embasado um sistema de penalidades de sequestro da liberdade; este que, a partir de construções discursivas ambivalentes, tensiona de forma paradoxal (contraditória e complementar) as dimensóes sociais e políticas de uma sociedade; dimensões em termos de poder, governabilidade, civilização e cidadania.

Na perspectiva das abordagens de enfrentamento, entendemos ser possível propor as seguintes linhas básicas:

1. Cognitivo-explicativas: as quais se concentram no (e priorizam o) desvelamento exploratório e/ou descritivo das expressōes identificáveis da questão penitenciária; a título de exemplo, estas podem se dedicar ao estudo de elementos normativos e políticos que àquelas expressôes se direcionam ou impactam de práticas e dinâmicas, bem como de representaçôes sociais, políticas e jurídicas (inclusive de origem judicial).

2. Cognitivo-combativas: as quais se caracterizam como abordagens que avançam no nível propositivo e de suplante dos paradoxos da questão penitenciária. Nessa perspectiva, podemos ainda diferenciar dois níveis: 2.1. o da redução de danos, para o qual nos servimos de uma pertinente manifestação de Lemgruber:

[...] acho importante enfatizar que a defesa da melhoria do sistema penitenciário não deve ser considerada uma postura reacionária ou idealista, na medida em que se advogam mudanças em uma instituição reconhecidamente falida, que serve para manter a lógica do Sistema de Justiça Criminal e o status quo. Enquanto não for possível nos livrarmos desse equívoco histórico que é a pena de prisão, não podemos, simplesmente, ficar de braços cruzados. Homens e mulheres são condenados à prisão todos os dias e não acredito que procurar minorar o sofrimento dessas pessoas corresponda a legitimar a ideologia que defende o aprimoramento do sistema prisional para continuar legitimando seu uso, com a justificativa hipócrita de que os infratores vão para as prisões para serem "ressocializados". A posição advogada aqui é muito diversa (1999, p. 161).

2.2. o abolicionista, cujo horizonte de enfrentamento está na suplantação das penalidades de sequestro, ou mesmo dos próprios sistemas de penalidades. Ao se apoiarem em trabalhos de autores como Louk Hulsman, Nils 
Christie e Thomas Mathiesen, esse nível abolicionista da abordagem se constitui através de teorias sensibilizadoras que, ainda que não possuam necessariamente o compromisso de oferecer soluçôes, têm potência crítica e variedade de opções alternativas (cf. Scheerer, 1989).

O mais relevante é que nenhuma dessas abordagens se permite simplificadora - aí se encontra a principal armadilha cognitiva das produções acadêmico-científicas e das iniciativas políticas (mesmo quando repletas de boas intenções) ao conduzi-las aos parâmetros das "filosofias re" (ressocialização, readaptação social, reinserção social, reeducação, repersonalização etc.). Segundo Zaffaroni (1991), o prefixo "re" induz à ideia de que algo falhou, o que justifica a intervenção tão somente corretora da falha ou daquele que a cometeu.

As filosofias "re", em que pesem suas diferenças, têm em comum a capacidade de mascarar não só a complexidade das sociedades e de seus fenômenos e instituições, mas também suas inerentes contradições. Ofuscam, ainda, a atuação seletiva do sistema penal, a qual se alimenta da vulnerabilidade de categorias sociais num contexto de contradiçôes.

Por último, em nossa perspectiva trata-se de algo indeclinável se ter em mente uma premissa ainda mais fundamental, a de que o "bom presídio" é um mito... Mesmo as mais adequadas e salubres estruturas, acompanhadas de dignos serviços de hotelaria e do acesso aos direitos da utopia da pena neutra, não retiram - apenas anestesiam - os efeitos perversos do sequestro. A prisão é uma instituição antissocial, deturpa qualquer possibilidade de reprodução de condições mínimas de sociabilidade saudável, motivo pelo qual é muito difícil se realizar análises que, ao final, concluam por uma solução de seus paradoxos. Nenhuma conclusão será pelo melhor, mas sim pela maior possibilidade de redução de danos ou por sua abolição.

\section{Referências Bibliográficas}

Aguirre, Carlos. (2009), "O cárcere na América Latina, 1800-1940”. In: MAIA, Clarissa Nunes et al. História das prisóes no Brasil. Rio de Janeiro, Rocco, vol. 1. Baratta, Alessandro. (1998), Criminología crítica y crítica del derecho penal. 5 ed. Ciudad de México, Siglo XXI.

CASTEL, Robert. (1998), As metamorfoses da questão social: uma crônica do salário. Petrópolis, Vozes. 
Coelho, Edmundo Campos. ([1987] 2005), A oficina do diabo - e outros estudos sobre criminalidade. Rio de Janeiro, Record.

DurKheim, Émile. (1995), Da divisão do trabalho social. São Paulo, Martins Fontes.

Elias, Norbert. (1993), O processo civilizador: formação do estado e civilização. Rio de Janeiro, Zahar, vol. 2.

. (2006), Escritos \& ensaios: Estado, processo, opinião pública. Rio de Janeiro, Zahar, vol. 1.

Foucault, Michel. (1991), Vigiar e punir: nascimento da prisão. Petrópolis, Vozes. . (1999), La verdad y las formas jurídicas. Barcelona, Gedisa. . (2003), Estratégia, poder-saber. Rio de Janeiro, Forense Universitária.

GARLAND, David. (1999), Castigo y sociedad moderna: un estudio de teoría social. Ciudad de México, Siglo Xxi.

(2008), A cultura do controle: crime e ordem social na sociedade contemporânea. Rio de Janeiro, Revan.

Giorgi, Alessandro de. (2006), A miséria governada através do sistema penal. Rio de Janeiro, Revan.

Gros, Frédéric. (2001) "Os quatro centros de sentido da pena”. In: GARAPON, Antoine et al. Punir em democracia: e a justiça será. Lisboa, Instituto Piaget.

Hulsman, Louk \& Celis, Jacqueline Bernat de. (1993), Penas perdidas: o sistema penal em questão. Rio de Janeiro, Luam.

LEMGruber, Julita. ([1983] 1999), Cemitério dos vivos: análise sociológica de uma prisão de mulheres. Rio de Janeiro, Forense.

Melossi, Dario \& Pavarini, Massimo. (1980), Carcel y fábrica: los origenes del sistema penitenciario, siglos XVI-XIX. Ciudad de México, Siglo XX.

Moraes, Pedro Rodolfo Bodê de. (2005), Punição, encarceramento e construção de identidade profissional entre agentes penitenciários. São Paulo, IBCCRIM.

Morin, Edgar. (2007), Ciência com consciência. Rio de Janeiro, Bertrand Brasil.

PECH, Thierry. (2001) "Neutralizar a pena”. In: GARAPON, Antoine et al. Punir em democracia: e a justiça será. Lisboa, Instituto Piaget.

Pereira, Potyara. (2009), Política Social: temas \& questôes. São Paulo, Cortez.

Ramalho, José Ricardo. ([1979] 2002), O mundo do crime: a ordem pelo avesso. São Paulo, IBCCRIM.

Rusche, Georg \& KirChHeImer, Otto. ([1939] 1999), Punição e estrutura social. Rio de Janeiro, Freitas Bastos.

Salla, Fernando. (1999), As prisões em São Paulo: 1822-1940. São Paulo, Annablume. Scheerer, Sebastian. (1989), "Hacia el abolicionismo". In: CoHen, Stan et al. Abolicionismo penal. Buenos Aires, Ediar.

Silva, Luiz Antonio Machado da. ([1987] 2005), "Introdução". In: CoElHO, 
Edmundo Campos. A oficina do diabo - e outros estudos sobre criminalidade. Rio de Janeiro, Record.

TeIXeIra, Alessandra. (2006), Do sujeito de direito ao estado de exceção: o percurso contemporâneo do sistema penitenciário brasileiro. São Paulo, dissertação de mestrado, Faculdade de Filosofia, Letras e Ciências Humanas da Universidade de São Paulo. Thompson, Augusto. (1991) A questão penitenciária. Rio de Janeiro, Forense.

WACQUANT, Loïc. (2007), Punir os pobres: a nova gestão da miséria nos Estados Unidos. Rio de Janeiro, Revan.

ZAFFARONI, Eugenio Raúl. (1991), "La filosofía del sistema penitenciario en el mundo contemporáneo". In: BELOFF, Mary Anne et al. (orgs.). Cuadernos de la cárcel. Buenos Aires, No Hay Derecho, pp. 36-62.

(2011), O inimigo no direito penal. Rio de Janeiro, Revan.

Zaffaroni, Eugenio Raúl \& Pierangeli, José Henrique (1997), Manual de direito penal brasileiro. São Paulo, Revista dos Tribunais.

\section{Resumo}

\section{A questão penitenciária}

Ao retomar a complexidade à qual potencialmente nos remete a expressão "questão penitenciária”, objetivamos contribuir para o desenvolvimento de abordagens que favoreçam o enfrentamento de seus contemporâneos e redimensionados paradoxos. Transitando por aportes da sociologia do castigo, da economia política da penalidade, dos sentidos dos discursos e do paradigma da complexidade, assumimos a questão penitenciária como complexa intersecção entre dimensões e políticas penais e sociais na sociedade moderna. Propomos premissas e enfoques estratégicos na expectativa de que se evitem as armadilhas de uma cognição simplificadora das realidades prisionais e/ou tensionamentos seduzidos por uma mitologia do "bom presídio". Palavras-chave: Prisão; Complexidade; Sistema Prisional; Questão penitenciária. 


\section{Abstract}

The penitentiary question

Re-examining the complexity evoked by the expression 'the penitentiary question,' I look to contributes to the development of approaches that favour confronting its contemporary paradoxes and new dimensions. Turning to the sociology of punishment, the political economy of penal systems, the analysis of discursive meanings and the paradigm of complexity, I take the penitentiary question to be a complex intersection between penal and social dimensions and policies in modern society. I propose a number of premises and strategic viewpoints in the endeavour to avoid the traps of a simplifying conceptualization of prison realities and/or tensions, seduced by a mythology of the 'good prison'.

Keywords: Prison; Complexity; Prison system; Penitentiary question.

Texto recebido em 10/1/2013 e aprovado em 24/1/2013.

Luiz Antônio Bogo Chies é professor vinculado ao mestrado em Política Social e à gradução em Direito na Universidade Católica de Pelotas (RS). E-mail $<$ labchies@uol.com.br>. 